\title{
Technological properties of cultivated Pleurotus ostreatus mushrooms and their influence on the choice of culinary processing methods
}

\author{
Nina Myachikova* \\ Belgorod State National Research University, 308015, Belgorod, Russia
}

\begin{abstract}
Pleurotus Ostreatus mushrooms are used as raw materials for public catering establishments. Features of the technological properties of this mushrooms affect the composition of operations and their parameters during mechanical processing and the choice of methods and features of thermal processing. Taking into account the peculiarities of the growth of this mushrooms and their morphological structure, a scheme of mechanical processing is presented. The duration and weight loss were determined for various methods of heat treatment. It was found that the weight loss during heat treatment decreases with an increase in the dry matter content. There is an inverse relationship between the content of bound water and the loss of mass: with an increase in the proportion of bound water, the mass loss during heat treatment decreases. It means that the weight loss during heat treatment of mushrooms is due to the loss of free water. Therefore when assessing the quality of raw materials at the stage of incoming control, it is necessary to control the content of dry matter in mushrooms, and take this indicator into account when developing formulations and establishing technological parameters, namely, losses during heat treatment.
\end{abstract}

Keywords: Pleurotus Ostreatus, technological properties of this mushrooms, culinary processing.

\section{Introduction}

Cultivated mushrooms Pleurotus Ostreatus is currently one of the most abundant mushrooms in the world, grown on many continents [1-3]. It is now the third highest in quantity of commercially produced mushroom in the world due to its high nutritional values. Pleurotus Ostreatus is a valuable mushroom of dietary importance. It is rich in primary and secondary metabolites and chemical elements of physiological significance. This type of mushroom contains vitamins: $\mathrm{C}$, niacin, riboflavin, thiamin, $\mathrm{B}_{12}$, oleic and linolenic acids, essential amino acids, as well as a number of other substances useful for the body. Due to its wide spectrum of biological activities, P. ostreatus is considered a medicinal mushroom. Fruiting bodies and extracts of P. ostreatus have found applications in the treatment of civilization related diseases, especially diabetes, arteriosclerosis and cancer[4-5].

\footnotetext{
* Corresponding author:myachikova@bsu.edu.ru
} 
For the cultivation of this type of mushroom, you can use various wastes that are generated in agriculture, forestry and food industries: corn cobs, sunflower husks, straw, etc. This allows to solve the problem of waste disposal. When growing oyster mushrooms, a large percentage of the substrate turns into fruiting bodies, which increases profitability and makes the production of this type of mushroom economically viable.

Thus, this type of mushroom finds more and more widespread use, including as a raw material for public catering enterprises. Consequently, it becomes necessary to study the technological properties of cultivated Pleurotus Ostreatus mushrooms and their changes during culinary processing.

\section{Materials and methods}

The object of the study was the cultivated mushrooms Pleurotus Ostreatus.Certain conditions were created when growing mushrooms (Table 1).

Table 1. Growing conditions for cultivated mushrooms Pleurotus Ostreatus.

\begin{tabular}{|c|c|}
\hline Indicators & Characteristic \\
\hline Substrate & Sunflower husk \\
\hline Illumination for fruiting & About $1000 \mathrm{~lx} / \mathrm{h}$ \\
\hline Temperature & $18 \ldots 20^{\circ} \mathrm{C}$ \\
\hline Humidity & $80 \ldots 90 \%$ \\
\hline Ventilation & $100 \ldots 200 \mathrm{~m}^{3} /$ hour per ton of substrate \\
\hline Harvesting time & $\begin{array}{c}\text { On the } 3^{\text {rd }} \ldots 4^{\text {th }} \text { day the appearance of germ (before the } \\
\text { onset of the sporulation period) }\end{array}$ \\
\hline
\end{tabular}

Sampling and preparation for testing were carried out in accordance with GOST R 566362015 [6].

The structural and mechanical properties of the tissue of fruit bodies were determined using a ST-2structometer[7].

The amino acid composition of the protein was determined after its hydrolysis with $6 \mathrm{~N}$ hydrochloric acid in sealed ampoules placed in a cabinet at a temperature of $100^{\circ} \mathrm{Cfor}$ 24 hours [8].

The composition and content of amino acids were assessed using the LKB 4151 "Alfa Plus" amino acid analyzer (Sweden) according to D.M. Spackman[9]. The principle of operation of the analyzer is based on the use of the continuous chromatography process.

The content of dry substances in mushrooms - by drying the sample to constant weight at a temperature of $100^{\circ} \mathrm{C}[10]$.

Content of free and bound water in mushrooms - refractometric [11].

Tryptophan content was determined by color reaction with ndimethylaminobenzaldehyde. Protein hydrolysis was carried out with a $10 \%$ alkali solution for $18 \ldots 20$ hours at a temperature of $37 \ldots 40^{\circ} \mathrm{C}$. To maintain the stability of the obtained color, gelatin was added before hydrolysis of the proteins. The amount of tryptophan was determined by the value of optical density, measured using a photoelectrocolorimeter [12].

Fractionation of proteins was performed by the Osborne method, which is based on the extraction of individual protein fractions with appropriate solvents with subsequent quantitative accounting of the isolated proteins [13].

\section{Results and discussion}


The technological process for the production of culinary products using mushrooms begins with their mechanical culinary processing. Traditionally, this process consists of a number of sequential operations:

- cleaning;

- soaking;

- washing;

- sorting;

- division into anatomical parts;

- shredding.

Depending on the type of mushrooms and their further use, some operations (soaking, washing, dividing into anatomical parts, shredding) may be missing.

Cleaning of Pleurotus ostreatus mushrooms involves only removing the lower part of the stem with the remnants of the substrate on which the mushrooms grow. The amount of waste in this case will depend on how the mushrooms were removed. There are two ways to remove the fruiting bodies: separation and cutting. In order to prevent decay of blocks with the substrate and the spread of pests (mushroom flies), the mushrooms are torn off. In this case, the presentation of the mushrooms deteriorates.A lot of substrate remains on the legs, which leads to an increase in the amount of waste during cleaning up to $(9.5 \pm 0.2) \%$. When cutting mushrooms, the waste is minimal and amounts to $(5.0 \pm 0.2) \%$. Market research for the sale of mushrooms shows that more often, both for sale and for processing, mushrooms are received, which are harvested using cutting.

Comparison of waste norms for cleaning Pleurotus ostreatus mushrooms with similar indicators given in the "Collection of recipes ...» [14]for champignons(24\%) shows that they are much lower. This is one of the benefits of Pleurotus ostreatus mushrooms.

The Pleurotus ostreatus mushrooms grow «in families». In order to ensure further processing, it is necessary to introduce such an operation as dividing the «families» into separate specimens.

After that, the mushrooms are washed. The purpose of this operation is to ensure the purity of raw materials and reduce contamination by microorganisms. The most effective is washing in running water, since with this method of washing the number of microorganisms decreases by $7 \ldots 12$ times (when washing in still water $-3 \ldots 4$ times) [15].

During the washing process, physical and chemical changes take place in the raw materials. As shown by the studies, even with the shortest washing $(\tau=30 \ldots 60 \mathrm{~s})$ in running water, allowing to achieve the goal of the operation, there is a significant increase in the mass of mushrooms due to the absorption of water by fruit bodies (Table 2).

Table 2. Change in the mass of Pleurotus ostreatus mushrooms after washing.

\begin{tabular}{|c|c|}
\hline Part of FB & Mass after washing, \% to the mass of unwashed mushrooms \\
\hline FB whole & $119.5 \pm 5.9$ \\
\hline Cap & $133.4 \pm 6.5$ \\
\hline Stalk & $126.2 \pm 6.3$ \\
\hline
\end{tabular}

As you can see, the largest change in mass is characteristic of the caps. Caps are more porous and therefore have a larger surface in contact with water than stalks. In addition, water can be trapped between the plates of the hymenophore, which is located under the pulp of the cap.

Fruit bodies completely absorb less water than caps and stalks taken separately. Perhaps this is due to the fact that when the caps are separated from the stalks, the structure of the tissue of the fruit bodies is additionally destroyed, and due to this, the surface area through which water penetrates into the inner space of the constituent parts of the fruit body increases. 
The papers present studies $[15,16]$ using various types of mushrooms. It is shown that in the process of washing, water partially displaces air and fills the gaps between hyphae, and the degree of absorption is within wide limits and depends mainly on the structure of the fruit body, determined by the species.

Naturally, there are a number of other factors affecting the absorption of water by the fruiting bodies of mushrooms during washing:

-growing conditions;

-the age of the fruiting body and its structure;

-storage duration;

-storage conditions;

-washing duration, etc.

All these factors, as shown by earlier studies [17], have a direct impact on the chemical composition, and, ultimately, on the technological properties of the mushrooms.

Studies carried out using Pleurotus ostreatus mushrooms from different batches have made it possible to establish, that within the same type of mushrooms, one of the factors affecting this indicator is the initial dry matter content in the mushrooms.

Studies have been carried out to establish the relationship between the content of dry matter in the fruit bodies as a whole and in individual parts of the fruit (caps and stalks) and water absorption during washing (Fig. 1).

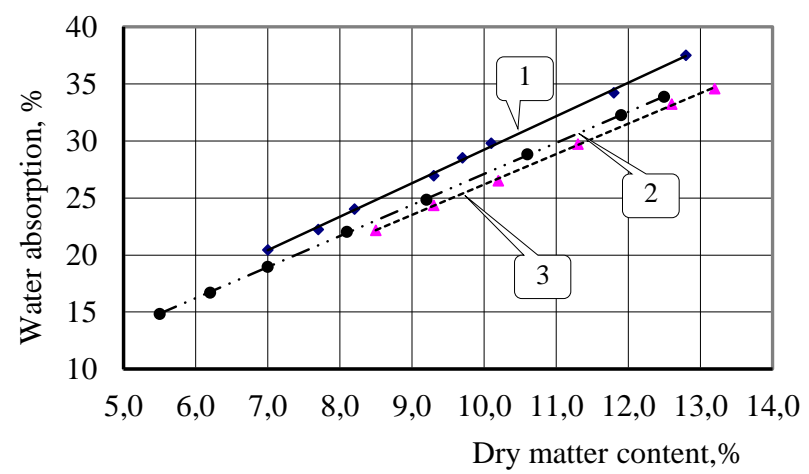

Fig. 1. Water absorption during washing, depending on the dry matter content: caps (1): $y=2,9356 x-$ 0,142; whole mushrooms (2): $y=2,7229 x-0,125$; stalks (3): $y=2,6661 x-0,487$.

The results obtained show that there is a directly proportional relationship between these values: the higher the dry matter content in the original samples before washing, the more the weight increases during the washing process. This suggests that during the washing process, water is bound not only physically (due to capillaries), but also physicochemically (due to interaction with biopolymers). Moreover, it should be assumed that proteins play the main role here, since there is a correlation between water absorption during the washing process and the protein content.

During the washing process, leaching of nutrients occurs, especially carbohydrates and nitrogenous substances $[15,16]$, therefore the recommended washing duration should be minimal. As a result of the experimental tests, the following washing parameters for Pleurotus ostreatus mushrooms were established: in running water for $30 \ldots 60 \mathrm{~s}$ at a temperature of $(18 \pm 2){ }^{\circ} \mathrm{C}$.

Depending on the further technological application, the mushrooms can be used whole; pre-divided into anatomical parts (caps and stalks) and use them entirely; chop (cutting by hand and using various mechanisms). In this case, weight loss occurs, i.e. production losses, the value of which was established in the course of experimental studies (Table 3). 
Thus, given that the Pleurotus ostreatus mushrooms are characterized by differences in the properties of caps and stalks, due to the peculiarities of the chemical composition and morphological structure, as well as the established parameters of individual operations, a basic technological scheme of mechanical culinary processing is proposed (Fig. 2).

Table 3. Production losses with various methods of mechanical culinary processing of Pleurotus ostreatus mushrooms.

\begin{tabular}{|l|c|}
\hline \multicolumn{1}{|c|}{ Method of mechanical culinary processing } & $\begin{array}{c}\text { Loss, in \% of the mass of } \\
\text { processed mushrooms }\end{array}$ \\
\hline Cutting (from whole fruit bodies) & $0.50 \pm 0.05$ \\
\hline Separation into anatomical parts & $0.30 \pm 0.05$ \\
\hline Separation into anatomical parts with subsequent slicing & $0.80 \pm 0.10$ \\
\hline
\end{tabular}

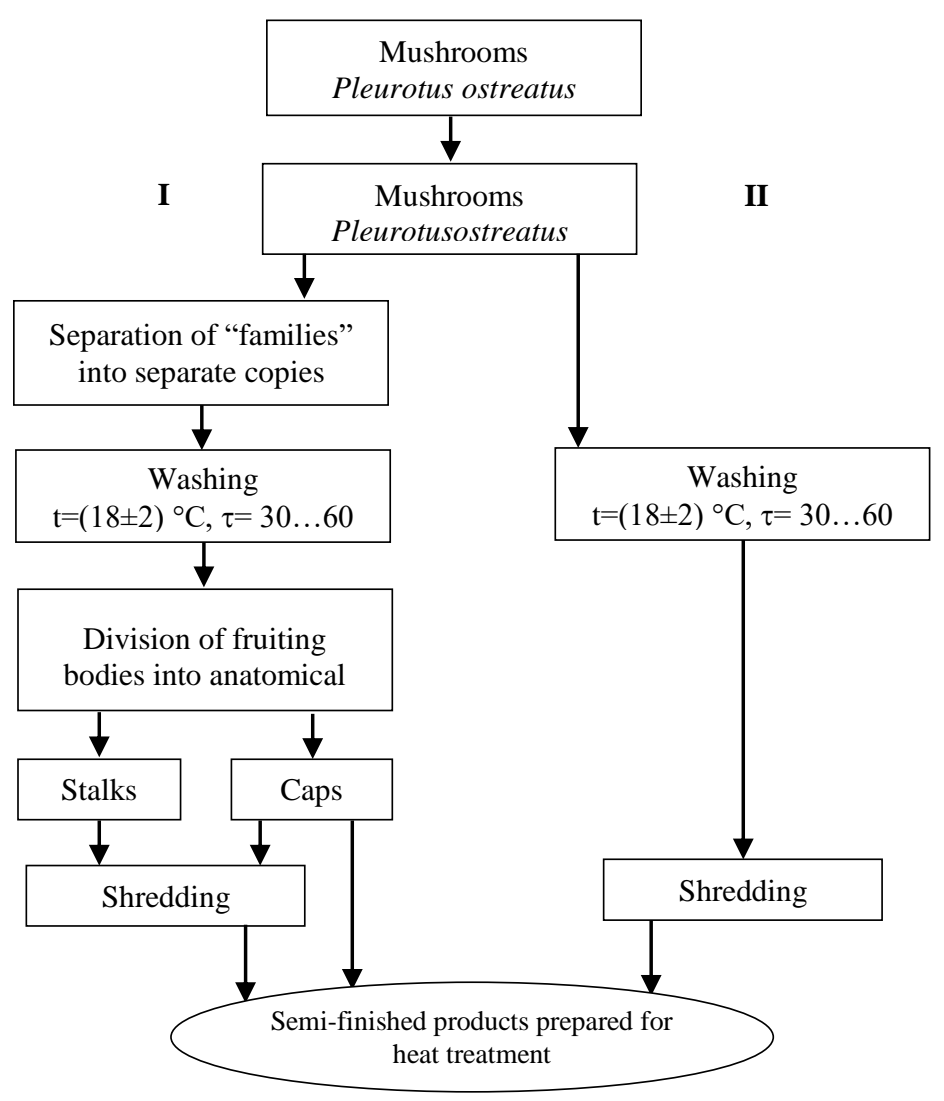

Fig. 2. Basic technological scheme of mechanical culinary processing of Pleurotus ostreatus mushrooms.

When implementing the first approach, difficulties arise that are associated, firstly, with the need for a possible sorting of raw materials, since various technologies may require mushrooms of various sizes, and secondly, with the laboriousness of the process, since the mechanization of this process has not been solved.

The second approach is less laborious and can be mechanized, since there are different mechanisms for shredding.

To bring to a state of culinary readiness, mushrooms are subjected to such methods of heat treatment as boiling, steaming, frying. Since there is no regulatory framework for 
Pleurotus ostreatus mushrooms, changes in technological properties were studied with various methods of heat treatment.

At the initial stage of the research, we used Pleurotus ostreatus, mushrooms grown on various substrates (wheat straw, sunflower husk, buckwheat waste). At the same time, it was noted that the mass of mushrooms during the heat treatment varied over a wide range. For example, when boiling whole mushrooms, weight loss was observed from 4.5 to $29.0 \%$, when boiling caps - from 9.6 to $30.0 \%$, and when boiling stalks - from $9.7 \%$ losses to $10.9 \%$ of the weld. Similar fluctuations were observed with other methods of heat treatment.

In this regard, Pleurotus ostreatus mushrooms grown on one type of substrate - sunflower husk were chosen as the object of the study. The use of this substrate allows an increase in the amount of protein in the mushrooms, which naturally increases the nutritional and biological value. In addition, this substrate is the most affordable, economical[18].

During heat treatment, various physicochemical changes occur. It is known that mushrooms are a source of complete proteins, and heat treatment affects the protein substances of products - their thermal denaturation, destruction and other irreversible changes occur. The results of studies on the influence of traditional methods of heat treatment (cooking and frying) on the amino acid composition of Pleurotus ostreatus mushrooms are presented in Table 4.

Table 4. Changes in the amino acid composition of Pleurotus ostreatus mushrooms during heat treatment.

\begin{tabular}{|c|c|c|c|c|c|}
\hline \multirow{3}{*}{ Amino acids } & \multicolumn{5}{|c|}{ Content in mushrooms } \\
\hline & \multirow{2}{*}{$\begin{array}{c}\text { raw, } \\
\text { mg /100 } \\
\text { g DM }\end{array}$} & \multicolumn{2}{|c|}{ boiled } & \multicolumn{2}{|c|}{ fried } \\
\hline & & $\begin{array}{c}\mathrm{mg} / \mathbf{1 0 0} \\
\text { g DM }\end{array}$ & $\begin{array}{c}\% \text { of } \\
\text { control }\end{array}$ & $\begin{array}{c}\mathrm{mg} / \mathbf{1 0 0} \\
\mathrm{g} \mathrm{DM}\end{array}$ & $\begin{array}{c}\% \text { of } \\
\text { control }\end{array}$ \\
\hline Indispensable amino acids & 6103 & 5544 & 90,8 & 5169 & 84,7 \\
\hline \multicolumn{6}{|l|}{ Including: } \\
\hline Isoleucine & 433 & 387 & 89,4 & 367 & 84,7 \\
\hline Leucine & 737 & 926 & 79,6 & 599 & 81,3 \\
\hline Lysine & 870 & 724 & 83,2 & 743 & 85,4 \\
\hline Methionine + cystine & 681 & 662 & 97,2 & 661 & 97,1 \\
\hline Phenylalanine + tyrosine & 1976 & 1616 & 81,8 & 1567 & 79,3 \\
\hline Threonine & 537 & 421 & 78,5 & 439 & 81,8 \\
\hline Tryptophan & 320 & 290 & 90,9 & 260 & 81,2 \\
\hline Valine & 549 & 518 & 94,4 & 533 & 97,1 \\
\hline Essential amino acids & 12319 & 11595 & 94,1 & 11744 & 95,3 \\
\hline \multicolumn{6}{|l|}{ Including: } \\
\hline Aspartic acid & 1603 & 1393 & 86,9 & 1494 & 93,2 \\
\hline Serine & 601 & 581 & 96,7 & 592 & 98,5 \\
\hline Glutamic acid & 2576 & 2483 & 96,4 & 2453 & 95,2 \\
\hline Proline & 4028 & 3931 & 97,6 & 3996 & 99,2 \\
\hline Glycine & 683 & 571 & 83,7 & 587 & 85,9 \\
\hline Alanine & 1798 & 1742 & 96,9 & 1750 & 97,3 \\
\hline Arginine & 718 & 627 & 87,3 & 640 & 89,1 \\
\hline Histidine & 312 & 267 & 85,6 & 232 & 74,3 \\
\hline Total amino acids & 18422 & 17139 & 93,0 & 16913 & 91,8 \\
\hline
\end{tabular}

Analysis of the amino acid composition shows that the mushrooms subjected to heat treatment contain all the amino acids contained in the feedstock. However, there are some 
changes in their quantitative content. So, during cooking, the total amount of amino acids decreases by $7.0 \%$. At the same time, the content of essential amino acids decreases by $9.2 \%$, and nonessential -by 5.9\%. Among the essential amino acids, the most thermolabile were threonine $(-21.5 \%)$, leucine $(-20.4 \%)$, the sum of phenylalanine and tyrosine $(-18.2 \%)$, lysine $(-16.8 \%)$.

In the process of frying, the proportion of essential amino acids decreases by $15.3 \%$, of nonessential ones - by $4.7 \%$, which leads to a decrease in the total amino acid content by $8.2 \%$. The greatest losses are observed in the content of phenylalanine and tyrosine, valine, leucine, threonine. The increase in amino acid losses during frying compared to boiling can be explained by a higher processing temperature.

The results of experiments on determining the duration of heat treatment and changes in weight with different methods of heat treatment of Pleurotus ostreatus mushrooms (mushrooms of standard sizes) in comparison with champignons are presented inTable 5.

Table 5. Duration of heat treatment and change in the mass of Pleurotus ostreatus mushrooms in comparison with champignons.

\begin{tabular}{|c|c|c|c|c|c|}
\hline \multirow{2}{*}{$\begin{array}{l}\text { Method of } \\
\text { heat } \\
\text { treatment }\end{array}$} & \multirow{2}{*}{$\begin{array}{l}\text { Part of FBand } \\
\text { method of } \\
\text { preparation for } \\
\text { heat treatment }\end{array}$} & \multicolumn{2}{|c|}{$\begin{array}{l}\text { Duration of heat treatment, } \\
(\tau \times 60) \mathrm{s}\end{array}$} & \multicolumn{2}{|c|}{$\begin{array}{c}\text { Change in mass during } \\
\text { heat treatment, } \%\end{array}$} \\
\hline & & Champignons & $\begin{array}{l}\text { Pleurotusos } \\
\text { treatus } * *\end{array}$ & $\underset{\text { ns* }}{\text { Champigno }}$ & $\begin{array}{l}\text { Pleurotusos } \\
\text { treatus } * *\end{array}$ \\
\hline \multirow[t]{3}{*}{ Boiling } & $\begin{array}{c}\text { Whole } \\
\text { mushrooms }\end{array}$ & $23 \pm 2$ & $43 \pm 2$ & $-30,0$ & $-(16,5 \pm 1,5)$ \\
\hline & Whole caps & - & $23 \pm 1,5$ & - & $-(22,8 \pm 2,0)$ \\
\hline & Whole stalks & - & $43 \pm 2$ & - & $+(5,5 \pm 0,5)$ \\
\hline \multirow[t]{2}{*}{$\begin{array}{l}\text { Stewing to } \\
\text { readiness }\end{array}$} & $\begin{array}{c}\text { Whole } \\
\text { mushrooms }\end{array}$ & - & $43 \pm 2$ & $-40,0$ & - \\
\hline & Whole caps & - & $23 \pm 1,5$ & - & $-(22,5 \pm 2,5)$ \\
\hline \multirow{2}{*}{$\begin{array}{l}\text { Stewing to } \\
\text { semi- } \\
\text { readiness }\end{array}$} & Caps, sliced & - & $10 \pm 1$ & - & $-(5,5 \pm 1,5)$ \\
\hline & $\begin{array}{c}\text { Mushrooms, } \\
\text { sliced }\end{array}$ & $8 \pm 2$ & $18 \pm 1$ & - & $+(6,8 \pm 1,2)$ \\
\hline \multirow[t]{4}{*}{ Frying } & $\begin{array}{c}\text { Mushrooms, } \\
\text { sliced, stewed } \\
\text { until half cooked }\end{array}$ & - & $23 \pm 2$ & $-50,0$ & $-(28,5 \pm 2,2)$ \\
\hline & $\begin{array}{l}\text { Caps, sliced, } \\
\text { stewed until half } \\
\text { cooked }\end{array}$ & - & $13 \pm 1$ & - & $-(21,0 \pm 2,0)$ \\
\hline & $\begin{array}{c}\text { Mushrooms, } \\
\text { sliced from raw }\end{array}$ & $18 \pm 2$ & $38 \pm 2$ & $-60,0$ & $-(47,0 \pm 2,0)$ \\
\hline & $\begin{array}{l}\text { Caps, sliced } \\
\text { from raw }\end{array}$ & - & $23 \pm 1,5$ & - & $-(25,0 \pm 2,5)$ \\
\hline
\end{tabular}

* Data from the «Collection of recipes ...» [14];

**Standard size mushrooms, mushroom moisture $-91.5 \pm 0.5 \%$

Taking into account the peculiarities of technological properties, the heat treatment was approached differentially, choosing more rational methods, taking into account the characteristics of this species of mushrooms. So, for example, the separate use of hats and stalks was used, which is not used in the heat treatment of champignons. Mushrooms were fried from raw and pre-stewed until half cooked.

It has been established that when boiling Pleurotus ostreatus mushrooms as a whole, the duration of the process is $(43 \pm 2) \times 60 \mathrm{~s}$ and is determined by the duration of bringing the stalks to readiness. Tissue strength during this period of time decreases 1.5 times for caps and 1.4 times for stalks, as evidenced by an increase in the degree of penetration (Fig. 3). 


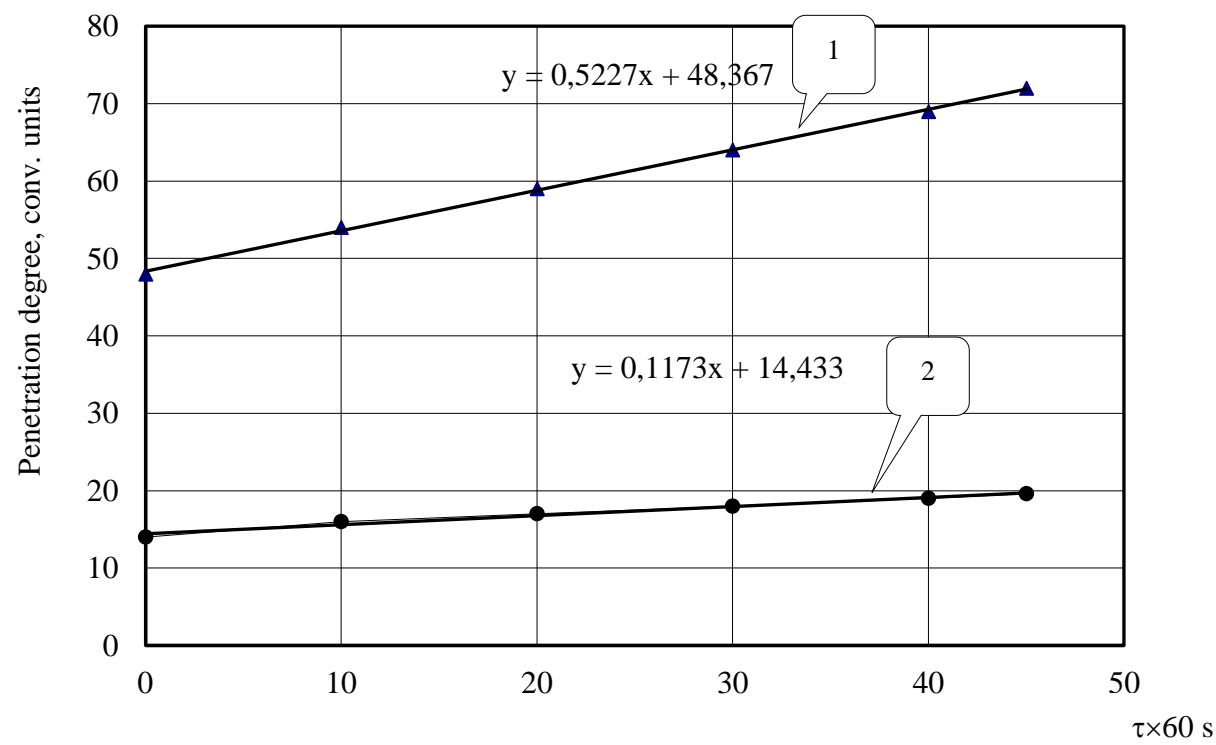

Fig. 3. Change in the degree of penetration of the caps and stalks of Pleurotus ostreatus mushrooms during the boiling process: 1 - caps, 2 - stalks.

The sensory evaluation of the product shows that during this time some of the caps are boiled and the quality of the product deteriorates significantly. In this regard, it is more expedient to use the caps and stalks separately, since the established dependences of the change in the degree of penetration on the duration of heat treatment for caps and stalks have significant differences (Fig. 3). With separate use of individual parts of the fruiting body, the duration of heat treatment is for stalks $(43 \pm 2) \times 60 \mathrm{~s}$, for caps $-(23 \pm 2) \times 60 \mathrm{~s}$, i.e., almost 2 times less.

Frying is also one of the most common ways to heat mushrooms, although this process cannot be called frying for mushrooms. Under the influence of high temperatures, the mushrooms release a significant amount of moisture, therefore, for the first $(7 \ldots 10) \times 60$ stewing take place, and only after the moisture has completely evaporated, frying begins directly. Mushrooms can be fried both raw and pre-stewed until half cooked. Due to the fact that the fruit bodies of Pleurotus ostreatus mushrooms are heterogeneous in size, it is recommended to cut them to ensure uniform heating. The duration of frying Pleurotus ostreatus, mushrooms, cut into slices from raw, is more than 2 times longer than the duration of frying champignons (Table 5). It is more expedient to fry only the caps, as this helps to reduce both the duration of the process and the losses by almost 2 times compared to frying sliced mushrooms.

The significant moisture content in the fruiting bodies of Pleurotus ostreatus mushrooms allows it to be subjected to such a method of heat treatment as stewing. Moreover, this process can be carried out without additional addition of water, i.e. in its own juice, and with the addition of water in the case of using fruit bodies with low humidity $(<85 \%)$. As well as boiling, it is more expedient to stew the caps and stalks separately. The caps can be stewed in whole or cut. When stewing in its entirety, small-sized caps (up to $40 \mathrm{~mm}$ ) should be used, while larger ones should be sliced. The duration of heat treatment when stewing mushrooms until cooked is the same as when boiling. 
As with boiling, with stewing of the caps, the heat treatment time is almost 2 times shorter than that of the whole mushroom heat treatment. Also, mushrooms can be stew until half cooked, subjecting them to further frying.

Stew until half cooked, the caps or mushrooms, cut into slices, are recommended as they are later used for frying. As with boiling, the stewing loses more when the caps are half cooked than when using the whole mushrooms. But in general, these losses are much lower, which can be explained by the reduction in the duration of heat treatment by almost 2 times.

One of the parameters characterizing the technological process is losses. The weight loss of Pleurotus ostreatus mushrooms when boiled as a whole $(16.5 \pm 1.5 \%)$ in comparison with champignons $(30.0 \%)$ is significantly lower, which, once again, confirms the influence of the structure of the fruiting body and the chemical composition of various types of mushrooms.

As can be seen (Table 5), when boiling the caps, maximum losses are observed $(22.8 \pm 2.0 \%)$, while boiling the stalks - weld $(5.5 \pm 0.5 \%)$. This is explained by the fact that the caps contain more moisture than the stalks; have a different morphological structure (looser and more porous), a larger surface area compared to the legs and, obviously, squeeze out more moisture. According to the available literature data $[17,18]$ and conducted studies, the caps contain more proteins than the stalks, since they are concentrated in the hymenial layer in the plates of mushrooms. Obviously, the weight loss during heat treatment also increases due to the dehydration process, which is a consequence of the denaturation of the cap proteins. At the same time, the stalks contain more fiber, which is able to partially swell and absorb moisture during heat treatment.

Losses when boiling mushrooms are entirely less than when boiling caps, since in this case the losses are compensated for by the weld characteristic of the stalks, the mass of which, as studies show, is $18.5 \ldots 45.0 \%$ of the mass of mushrooms.

When stewing whole caps until cooked, losses during heat treatment are within the same limits as during boiling.

The maximum weight loss is observed when frying Pleurotus ostreatus, mushrooms, cut into slices from raw, which is also typical for mushrooms. At the same time, these losses are somewhat lower $(47.0 \pm 2.0 \%)$, than in mushrooms $(60.0 \%)$. When frying caps, the loss is almost 2 times less. This is possibly due to the fact that the duration of heat treatment is reduced in this case by 2 times.

As the studies show, in order to reduce losses during frying, it is advisable to subject the mushrooms to a combined processing: stewing until half cooked for $(18 \pm 1) \times 60$ swith the addition of $20 \ldots 25 \%$ liquid, and then directly fry the main method for $(23 \pm 1.5) \times 60 \mathrm{~s}$. In this

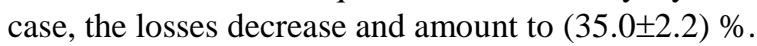

The change in the mass of mushrooms during heat treatment is influenced by a number of objective factors, one of which is the content of dry matter. The results of studies to establish the relationship between dry matter content and weight loss during heat treatment are presented in Fig. 4, as well as between water content (total, free and bound) and weight loss during heat treatment (when cooking caps) are presented in Fig. 5.

Analysis of the obtained results shows that with an increase in dry matter content, weight loss during heat treatment decreases (Fig. 4).

The results of the analysis of the relationships between the content of total and free water and the loss of mass during heat treatment (Fig. 5) indicate that there is a direct relationship between these values, i.e. with a decrease in total and free water, the weight loss decreases. There is an inverse relationship between the content of bound water and the loss of mass: with an increase in the proportion of bound water, the mass loss during heat treatment decreases. It follows from this that the loss of mass during the heat treatment of mushrooms is primarily due to the loss of free water, and the greater its share, the higher they are. 


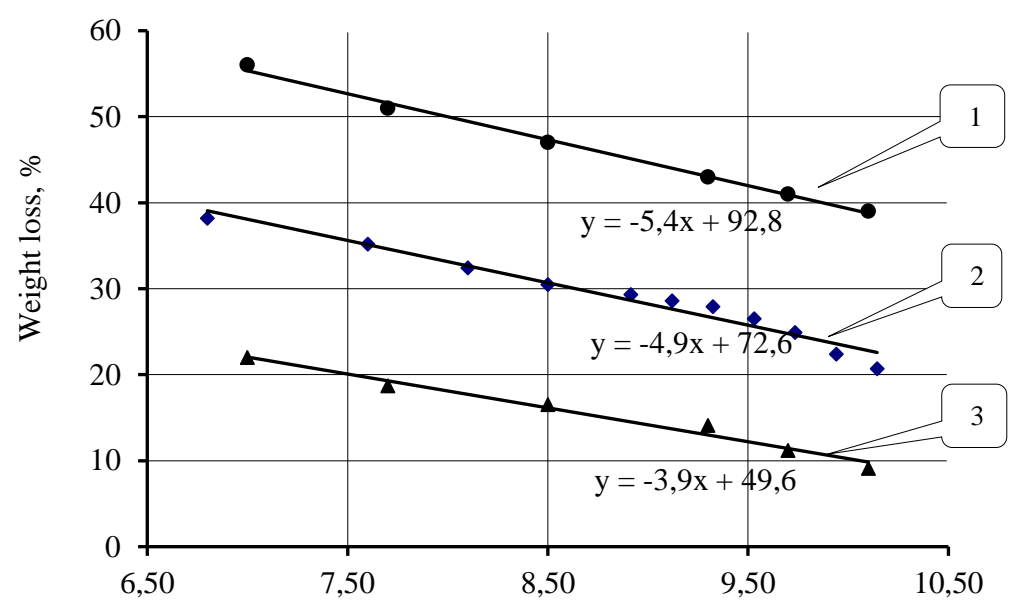

Dry matter content, $\%$

Fig. 4. Weight loss during frying (1), combined heat treatment (2) and boiling (3) depending on the dry matter content.

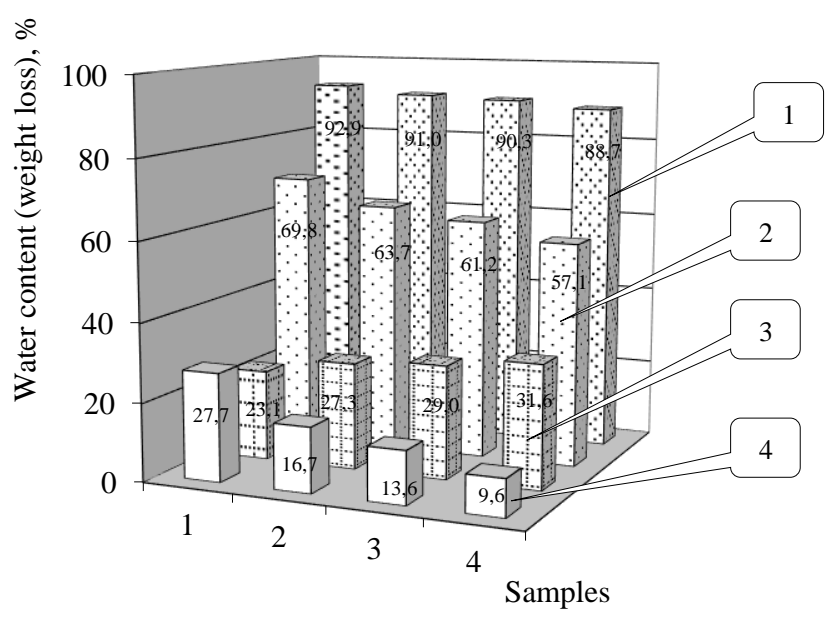

Fig. 5. Water content (total (1), free (2), bound (3)) and weight loss (4) when cooking Pleurotus ostreatus mushroom caps.

It should be noted that the lack of standardization of dry substances in mushrooms (according to the current regulatory documentation) makes it impossible to normalize the technological parameters of recipes for culinary products.

Using linear mathematical models of dependencies (Fig. 4), for which the linear form of connection adequately describes the process weight loss; in accordance with Fisher's criterion, the model is statistically significant, and the coefficients of the model, according to the Student's coefficients, agree well with the experimental data, it is possible to make adjustments regarding the mass of mushrooms in standard formulations developed taking into account a certain dry matter content in mushrooms $(8.5 \%)$, taken as standard. Thus, 
scientifically substantiate the rationing of raw materials in recipes and predict the output of finished products.

In particular, formulas have been proposed that make it possible to calculate the net mass of raw mushrooms containing different amounts of dry substances in order to obtain the mass of heat-treated mushrooms given according to the recipe:

$$
\begin{gathered}
M_{n t}=\frac{\mathrm{M}_{h / t}}{100 \times(0,50+0,04 \times)}-\text { when boiling mushrooms } \\
M_{n t}=\frac{\mathrm{M}_{h / t}}{100 \times(0,07+0,05 \times)}-\text { when frying mushrooms } \\
M_{n t}=\frac{\mathrm{M}_{h / t}}{100 \times(0,27+0,05 \times)}-\text { with combined heat treatment of mushrooms }
\end{gathered}
$$

where $M_{\mathrm{nt}}-$ net mass of raw mushrooms, $\mathrm{kg}$;

$M_{\mathrm{h} / \mathrm{t}}-$ mass of heat-treated mushrooms, $\mathrm{kg}$;

$x$ - dry matter content in mushrooms, $\%$.

Within the specified accuracy, the regression coefficients describing the process of frying and combined heat treatment are the same. The used modeling methods are adapted to the technological process of heat treatment of mushrooms.

\section{Conclusions}

Thus, the features of the technological properties of cultivated Pleurotus Ostreatus mushrooms affect the composition of operations and their parameters at the stage of mechanical culinary processing, as well as the choice of methods and features of thermal culinary processing.

Taking into account the research carried out when assessing the quality of raw materials at the stage of incoming control, it is necessary to control the content of dry substances in mushrooms, and also take this indicator into account when developing formulations and establishing technological parameters, namely losses during heat treatment.

\section{References}

1. F.A. Zakil, M.S.M.Sueb,R. Isha, AIP Conference Proceedings, 2155, 020055(2019)

2. R. Naraian, B. Dixit, Arch. Biotechnol. Biomed.,1 (2017)

3. B.O. Ekute, Journal of Applied Sciences and Environmental Management, 22 (11) (2018)

4. G. Titas, S. Aparajita, D. Arpita, J. Gynecol Women's Health,14(1), 555876 (2019)

5. K. Piska, K. Sułkowska-Ziaja, B. Muszyńska,Acta Sci. Pol. Hortorum Cultus, 16 (1) (2017)

6. GOST R 56636-2015. Fresh cultivated oyster type mushrooms. Specifications (Standartinform, Moscow, 2019)

7. Instructions for using the attachments on the structurometer ST-2

8. V.G. Kanarev, Methods of protein and aminoacid analysis of plants (Leningrad, 1973)

9. D.M. Spackman, S. Moor, W.A. Stein, Analytical Chemistry,30(7) (1958) 
10. GOST 28561-90. Fruit and vegetable products. Methods for determination of total solids or moisture (Standartinform, Moscow, 2011)

11. A.I. Ermakova, Methods of biochemical research of plants (Agropromizdat, Leningrad, 1987)

12. A.I. Ermakov, N.P. Yarosh, A.A. Mikhailov, Applied biochemistry and Microbiology, 3(1) (1967)

13. I.I. Vasilenko, V.I. Komarov, Grain quality assessment (Agropromizdat, Moscow, 1987)

14. Collection of recipes of dishes and culinary products for public catering enterprises (Economy, Moscow, 1983)

15. Yu.T. Zhuk, Canning and storage of mushrooms (biochemical bases) (Light and food industry, Moscow, 1982)

16. Yu.T. Zhuk, Research of edible mushrooms in connection with the problem of effective use of natural resources (Moscow, 1975)

17. P.A. Sychev, N.P. Tkachenko, Mushrooms and mushroom farming (Stalker, Donetsk, 2003)

18. N.A. Bisko, I.A. Dudka, Biology and cultivation of edible mushrooms of the genus oyster mushroom (Naukova dumka, Kiev, 1987) 